\title{
Ibuprofen Arginate for Rapid-Onset Pain Relief in Daily Practice: A Review of Its Use in Different Pain Conditions
} This article was published in the following Dove Press journal:
Journal of Pain Research

\section{Juan Pérez Cajaraville}

Pain Unit, Grupo Hospitalario Universitario HM (Hospitales de Madrid), Madrid, Spain
Correspondence: Juan Pérez Cajaraville Pain Unit, Grupo Hospitalario

Universitario HM (Hospitales de Madrid), Pl. del Conde del Valle Súchil 16, Madrid E-280I5, Spain

Tel +34 62920099l

Email jpcajaraville@hmhospitales.com

\begin{abstract}
Ibuprofen is one of the most frequently used analgesics. One of the concerns related with the oral administration of conventional ibuprofen is the relatively slow absorption, which is clinically a relative inconvenience when rapid-onset analgesic effect is required in patients suffering from acute moderate/severe pain. A new oral dosage formulation of ibuprofen containing the L-arginine salt of ibuprofen (ibuprofen arginate) has been commercialized for more than two decades, but data reported in the literature are relatively scarce. This article presents salient findings on pharmacokinetics, pharmacological activity, clinical efficacy and tolerability of ibuprofen arginate, with the purpose to provide clinicians with a summary overview of some frequent acute pain conditions, such as dental pain, dysmenorrhea, headache or postoperative pain in which ibuprofen arginate may be considered the drug of choice in individual patients.
\end{abstract}

Keywords: ibuprofen arginate, arginine, analgesic efficacy, pharmacokinetics

\section{Introduction}

Millions of patients each year suffer from episodes of acute pain, ranging from mild to severe, as a result of numerous conditions in the fields of trauma, medical diseases and surgery. ${ }^{1,2}$ Acute pain usually lasts for less than 7 days but often extends up to 30 days, and for some conditions, acute pain episodes may recur periodically. ${ }^{3}$ Pain is a public health issue worldwide, affects all populations regardless of age, gender, economic status, race or geography, and remains the most common cause for physician consultation, emergency department visits and hospital admission. ${ }^{4}$ Also, chronic pain is a common, complex and distressing problem, with a significant impact on patients, society and healthcare systems. ${ }^{5}$ The Global Burden of Disease study 2018 reaffirmed that the high prominence of pain and pain-related diseases are the leading cause of disability and disease burden globally. ${ }^{6}$

Despite the availability of effective pharmacological and non-pharmacological approaches, the management of pain remains inadequate across different treatment settings, with a substantial proportion of patients continuing to experience pain of mild to moderate intensity. ${ }^{7}$ Inadequately managed acute pain has a negative impact on numerous aspects of patient's health and may increase the risk of developing chronic pain. ${ }^{8}$ Physicians commonly encounter challenging acute pain scenarios, with key decisional dilemmas regarding the selection of medicines to provide 
adequate pain relief in order to facilitate recovery, improve function and quality of life, as well as minimizing adverse effects and the need of prescribing of opioids. On the other hand, it has been demonstrated some shortcomings in physicians' knowledge about the optimal treatment and expected time course for acute pain conditions presenting to the primary care setting. ${ }^{9}$

The use of prescribed and, in particular, over-the-counter (OTC) analgesics is very common at population level, and different studies have shown overall prevalences ranging between $8.5 \%$ for daily analgesic use, $13.6 \%$ a few times a week, $47 \%$ once a week, and $76 \%$ once a month. ${ }^{10-13}$ Ibuprofen was the first non-aspirin non-steroidal antiinflammatory drug (NSAID) to be approved for OTC use and is widely considered to be the best tolerated drug of its class. Low-dose, OTC ibuprofen has been used for pain relief for over 30 years without any obvious major health issues. ${ }^{14}$ In a systematic review of 39 Cochrane reviews of randomized controlled trials (RCTs) that had examined the analgesic efficacy of drug interventions in the postoperative pain model, fast-acting formulations of ibuprofen 200 and $400 \mathrm{mg}$ showed values of the number needed to treat (NNT) close to 2 for the outcome of at least $50 \%$ pain relief over 4-6 hours compared to placebo. ${ }^{15}$ Ibuprofen was also more favorable than paracetamol and aspirin at various doses with NTT values of 3 and above.

Ibuprofen is an NSAID with analgesic, antiinflammatory and antipyretic properties that has proven to be safe and effective for treating many different types of pain. Currently available in the market are preparations in which bioavailability of ibuprofen is increased by salification with various salts, in particular, L-arginine (ibuprofen arginate). Ibuprofen arginate was firstly introduced in the market in 1994 in Spain (Espidifen ${ }^{\circledR}$, Zambon S.A. U.), and is now commercially available in several other European countries with different brand names. However, despite widespread use of the drug for decades, a narrative review of the available evidence focused on clinically useful aspects of the mechanism involved in the rationale of combining ibuprofen with L-arginine, pharmacological properties, analgesic efficacy, tolerability and safety of ibuprofen arginate has not been previously reported. The characteristics of other salt forms of ibuprofen are not included in the present review.

\section{Methods}

Medical literature published since 1990 on ibuprofen and/ or arginine was identified using MEDLINE/PubMed database, with the MeSH major terms "ibuprofen" and "arginine" with "therapeutic use", "pharmacokinetics", and "adverse effects" as subheadings. In addition, using the PubMed Advanced Search Building (builder Title and Title/Abstract) the free terms "ibuprofen", "arginine" and "arginate" were used separately and combined. Language restrictions included documents published in English and Spanish, or in any other language for which an English abstract was available. The reference lists of published articles were checked for further information. Additional literature was provided by the company manufacturing the drug when articles were published in journals not indexed in PubMed. Some information regarding the development of the formulation and the date of commercialization was directly asked to the company. The search was performed on May 12, 2020.

\section{Pharmacokinetics of Ibuprofen Arginate}

Ibuprofen, ( \pm )-(R,S)-2-(4-isobutylphenyl)-propionic acid, is a chiral 2-arylpropionic acid derivative NSAID. As far as the mechanism of action, ibuprofen is a non-selective inhibitor of cyclooxygenase-1 (COX-1) and -2 (COX-2) derived prostaglandin biosynthesis. Ibuprofen demonstrates marked stereoselectivity, with substantial unidirectional bioinversion of the R-(-) enantiomer to the S-(+) enantiomer, which possess most of the anti-inflammatory activity. ${ }^{16,17}$ Commercial formulations come as many kinds of tablets in the market, and one of the concerns with the oral administration of conventional ibuprofen is the relatively low absorption, with peak plasma concentrations usually reached within $1.5-3 \mathrm{~h}$ after oral ingestion. This relatively low absorption rate may eventually limit the usefulness of the drug when rapid alleviation of pain is required. On the other hand, when oral doses of racemic ibuprofen are administered, the metabolic inversion process of R-(-) ibuprofen (50-60\%) to yield the active S-(+) ibuprofen depends on the absorption rate; thus, modifications on the dosage form could affect the extent of inversion and the bioavailability if the active S- $(+)$ enantiomer. ${ }^{18,19}$ Therefore, an analgesic formulation with enhanced absorption rate of S-(+) ibuprofen may be more effective in treating acute pain.

Ibuprofen arginate is formed by combining the racemic ibuprofen with the amino acid L-arginine (Figure 1), which has been added as gastrointestinal absorption enhancer, ${ }^{20}$ which in turn could affect the extent of 

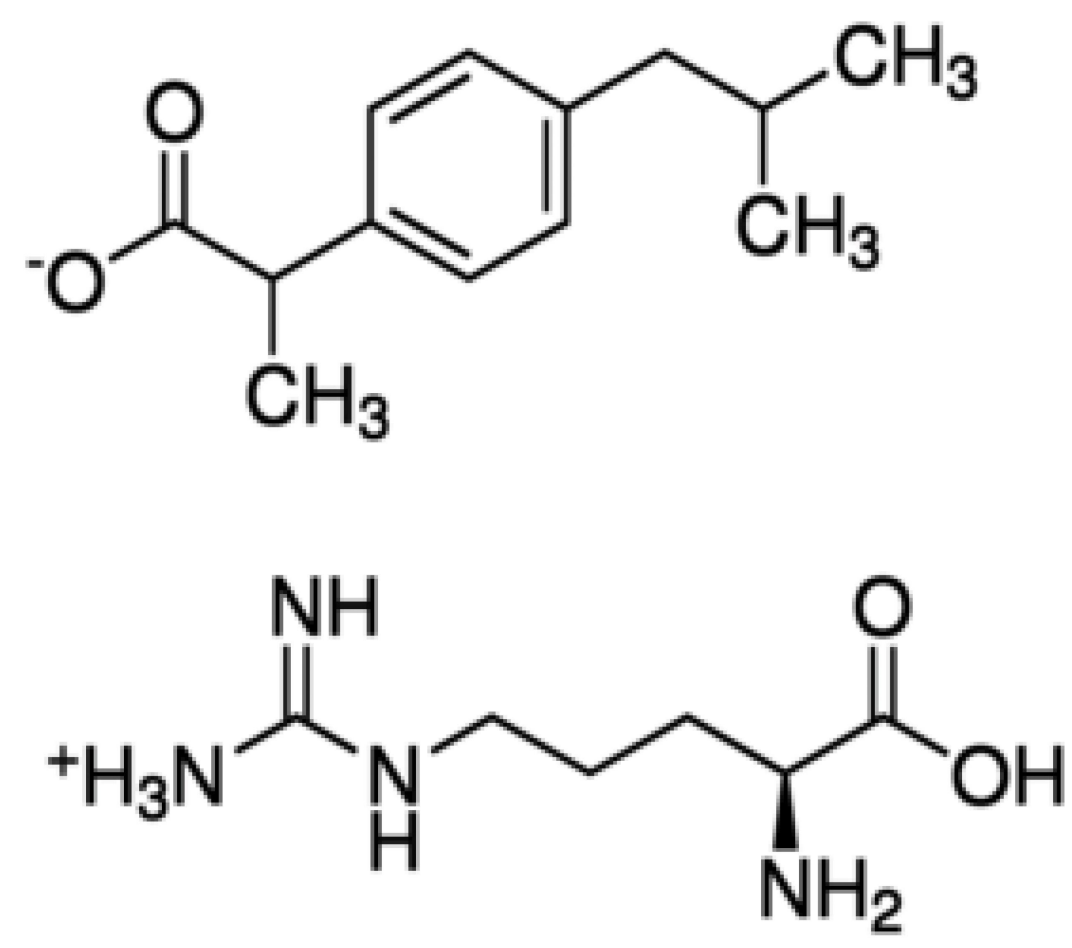

Figure I Structural formula of ibuprofen and L-arginine.

inversion and the bioavailability of the active S-(+) enantiomer and the therapeutic activity of ibuprofen. In a pharmacokinetic study of ibuprofen enantiomers, the mean percentage of bioinversion of the R-(-) ibuprofen to the $\mathrm{S}(-)+$ enantiomer after administration of the racemic ibuprofen arginine formulation averaged $49 \% .^{21}$ It appears that R-(-) ibuprofen undergoes inversion to the $\mathrm{S}(-)+$ enantiomer through an acyl-Co thioester by the enzyme $\alpha$ methylacyl-coenzyme A racemase (encoded by gene $A M A C R)$, which occurs systemically predominantly in the liver and pre-systemically in the gut as well. ${ }^{22}$

Oral formulations of ibuprofen arginate produced peak plasma levels that are significantly higher than those produced by standard formulations of ibuprofen, presenting concentrations greater than $30 \mu \mathrm{g} / \mathrm{mL}$ at 5 minutes and reaching peak concentrations at 15 to 30 minutes after administration compared with 1.5-3 hours after oral ingestion of ibuprofen. The relative bioavailability of the two preparations is similar, as are the mean elimination halflife, total area under the concentration-time curve (AUC), volume of distribution and plasma clearance. ${ }^{16}$
In one of the first studies that compared the pharmacokinetics and bioavailability of ibuprofen and ibuprofen arginate in 16 healthy volunteers treated with single oral doses of 200 and $400 \mathrm{mg}$, quicker absorption and significantly higher plasma bioavailability during the first hour after administration in subjects treated with ibuprofen arginate at both doses was observed. ${ }^{23}$ As shown in Table 1, pharmacokinetic parameters were more favorable for ibuprofen arginate as compared to ibuprofen free acid, and the shortening in the absorption time and the increase in the plasma concentrations did not cause any changes in the bioavailability as measured by the AUC. In a comparative study of the pharmacokinetics of ibuprofen arginate $(600 \mathrm{mg})$ versus dexibuprofen (the active $\mathrm{S}-(+)$ enantiomer) $(400 \mathrm{mg})$ in 24 healthy volunteers, ${ }^{24}$ ibuprofen arginate showed a $45 \%$ higher maximum plasma concentration $\left(\mathrm{C}_{\max }\right)$ and time to peak concentration $\left(\mathrm{T}_{\max }\right) 2 \mathrm{~h}$ sooner (Table 1$)$. In both studies, there were statistically significant differences in $\mathrm{C}_{\max }$ and $\mathrm{T}_{\max }$ in favor of ibuprofen arginate with higher $\mathrm{C}_{\max }$ and shorter $\mathrm{T}_{\max }$ values, indicating that absorption 
Table I Pharmacokinetic Parameters of Ibuprofen and Ibuprofen Arginate Formulations in Two Studies in Healthy Volunteers

\begin{tabular}{|c|c|c|c|c|c|c|}
\hline \multirow{2}{*}{$\begin{array}{l}\text { Pharmacokinetic } \\
\text { Parameters }\end{array}$} & \multicolumn{3}{|c|}{ Study of 16 Healthy Volunteers ${ }^{23}$} & \multicolumn{3}{|c|}{ Study of 24 Healthy Volunteers ${ }^{24}$} \\
\hline & $\begin{array}{l}\text { lbuprofen Arginate } \\
400 \mathrm{mg}\end{array}$ & $\begin{array}{l}\text { Ibuprofen Free Acid } \\
400 \mathrm{mg}\end{array}$ & $P$ value & $\begin{array}{l}\text { Ibuprofen Arginate } \\
600 \mathrm{mg}\end{array}$ & $\begin{array}{l}\text { Dexibuprofen } \\
400 \mathrm{mg}\end{array}$ & $P$ value \\
\hline$A \cup C_{0-4 h}(m g \cdot h / L)$ & $115.9(19.0)$ & II $4.3(29.0)$ & NS & & & \\
\hline $\mathrm{AUC}_{0-12 \mathrm{~h}}(\mathrm{mg} \cdot \mathrm{h} / \mathrm{L})$ & & & & $102.2(29)$ & $105.0(29.2)$ & NS \\
\hline$A \cup C_{0-\infty}(m g \cdot h / L)$ & $119.5(21.2)$ & $119.4(31.2)$ & NS & $105.0(29.8)$ & $107.8(30.5)$ & NS \\
\hline $\mathrm{C}_{\max }(\mathrm{mg} / \mathrm{L})$ & $56.4(13.6)$ & $43.0(8.5)$ & $<0.05$ & $38.4(8.5)$ & $26.5(7.7)$ & $<0.001$ \\
\hline $\mathrm{T}_{\max }, \min$ or $\mathrm{h}$ & $24.4(16.9)$ & $63.7(29.7)$ & $<0.05$ & $0.33(1.5)$ & $2.25(3)$ & $<0.001$ \\
\hline$T_{1 / 2}, \min$ or $h$ & $110.0(21.9)$ & $117.0(26.7)$ & NS & $2(0.3)$ & $1.8(0.3)$ & $<0.006$ \\
\hline
\end{tabular}

Note: Data expressed as mean (standard deviation, SD).

Abbreviation: NS, not significant.

of the active $\mathrm{S}(-)+$ enantiomer was higher and quicker as compared to standard ibuprofen formulation. ${ }^{23,24}$

\section{Protective Action Against Gastric Mucosal Damage}

Gastrointestinal complications are well-recognized side effects of NSAIDs. The upper gastrointestinal side effects include troublesome symptoms with or without mucosal injury, asymptomatic mucosal lesions, and serious complications, even death. It has been shown that about 30-50\% of NSAIDs users have endoscopic lesions (erosions, subepithelial hemorrhages, ulcerations) mainly located in the gastric antrum, and often without clinical manifestations. On the contrary, up to $40 \%$ of NSAIDs users have symptoms, the most frequent being gastroesophageal reflux disease and dyspepsia. ${ }^{25}$ However, although the use of NSAIDs has been associated with a 3- to 5-fold increase in the risk of upper gastrointestinal complications, ${ }^{26,27}$ the risk varies between individual NSAIDs. Within the European Community's Seventh Framework Programme, the Safety Of non-Steroidal anti-inflammatory drugs (NSAIDs) [SOS] project, a systematic review and metaanalysis of 28 observational studies provided summary relative risks (RR) of upper gastrointestinal complications associated with NSAIDs. ${ }^{28}$ Pooled RR ranged from 1.43 (95\% confidence interval [CI] 0.65-3.15) for aceclofenac to 18.45 (95\% CI 10.99-30.97) for azapropazone, with RR less than 2 for ibuprofen (1.84, 95\% CI 1.54-2.20). Moreover, various studies including meta-analyses have shown that the nature and frequency of gastrointestinal adverse effects due to ibuprofen intake are similar to those observed with the use of paracetamol, naproxen or placebo. $^{29-32}$

The gastrolesive effects of ibuprofen can be counteracted by the biological actions of nitric oxide (NO). In this respect, salification with arginine appears of particular biological interest because L-arginine is the substrate of the NO synthesizing enzymes, the NO synthases (NOS). NO is a short-lived messenger that has pleiotropic actions, with protective antiapoptotic effects on epithelial cells of the gastrointestinal tract, ${ }^{33}$ increase mucin formation, promote synthesis of prostaglandins E2 and gastrin, ${ }^{34}$ and can synergize with the action of prostacyclin on gastric epithelial cells. ${ }^{35}$ In addition, NO may increase blood flow in the gastric mucosa and enhance ulcer healing because of its vasodilating and angiogenic properties. ${ }^{36}$

In rats gastric mucosa, the mechanisms of L-arginine protection in ibuprofen-induced gastric damage were mainly due to the increase in $\mathrm{NO} /$ prostaglandin production in the stomach. ${ }^{37}$ Also, the simultaneous administration of equimolar doses of ibuprofen and L-arginine offered significant protection compared with gastrolesive doses of ibuprofen alone, with an important decrease in $\mathrm{mm}^{3}$ and score of gastric damage, ratio of lesionated stomach/total stomach evaluated, and presence of hemorrhage, with the extent of this protective action comparable to that observed with antisecretory (ranitidine and roxatidine) and cytoprotective (misoprostol) reference dugs. ${ }^{38}$ In studies in healthy volunteers, ${ }^{39,40}$ treatment with ibuprofen-arginate showed a tendency to cause fewer gastric endoscopic lesions and was associated with a significantly lower rate of clinical adverse effects than ibuprofen, which could be explained by the increase in NO synthesis induced by arginine. It also has 
been proved that arginate salts could lack of undesired cardiovascular effects. ${ }^{41}$ It has been shown that ibuprofen arginate provides an arginine source able to reverse the effects of the asymmetric dimethylarginine (ADMA), which is an endogenous NOS inhibitor, leading to reduced endothelial NOS activity and associated endothelial dysfunction; ADMA is a cardiotoxic hormone and biomarker of cardiovascular risk whose effects can be prevented by L-arginine. $^{42,43}$

\section{Analgesic Efficacy and Tolerability of Ibuprofen Arginate}

The analgesic efficacy of ibuprofen arginate has been examined in different clinical trials and observational studies with placebo or other NSAIDs as comparators. In these conditions that can cause severe pain, ibuprofen arginate provides a rapid and effective analgesic effect.

\section{Dental Pain}

Pain following removal of impacted third molar teeth has proven to be a useful clinical model for evaluating oral analgesics, and NSAIDs demonstrate high potency in this model, reflecting the large contribution that peripheral prostaglandins may make to the pathophysiology of postoperative pain. ${ }^{44,47}$ In this model, five randomized singleor double-blind, parallel-group and placebo-controlled trials have reported the analgesic efficacy and tolerability of ibuprofen arginate versus ibuprofen or other NSAIDs (naproxen, aceclofenac) and placebo. ${ }^{45-49}$ The main results of these studies are described in Table 2. Except for one study, in which ibuprofen arginate was administered $15 \mathrm{~min}$ before surgery for the prophylaxis of pain, ${ }^{45}$ the remaining studies evaluated the analgesic efficacy and tolerability after dental surgery, usually over the first 6 hours postoperatively. In these studies, efficacy was based on overall assessments of pain intensity and pain relief measures, including pain intensity differences from baseline, pain relief scores, total pain relief, and peak pain relief. Key summary measure for onset of analgesia was time to meaningful pain relief. In one study, duration of pain relief was evaluated by analyzing the time to remedication. ${ }^{48}$ In three studies, ${ }^{47-49}$ two doses of ibuprofen arginate $(200,400 \mathrm{mg})$ and ibuprofen $(200,400 \mathrm{mg}$ ) were evaluated and compared with placebo. Main findings were statistically significant differences of active treatments versus placebo, and significant differences of both doses of ibuprofen arginate versus the corresponding doses of ibuprofen. Overall, ibuprofen arginate $400 \mathrm{mg}$ was the most effective. Results in the dental pain model indicate that ibuprofen arginate when taken at doses equivalent to standard commercially available ibuprofen formulations produces analgesia that is significantly faster in onset. Also, patients treated with ibuprofen arginate rated its overall effectiveness higher than those patients treated with conventional ibuprofen.

Adverse event (AE) profiles (overall and individual side effects) were similar across all treatment groups, with somnolence, headache, dizziness, nausea and vomiting as the most frequent complaints. The rate of AEs, however, varied between 6 and $14 \%$ in the study of Desjardins, ${ }^{49}$ around $27 \%$ in the study of Mehlisch et al, ${ }^{48}$ and $36-43 \%$ in the study of Black et al. ${ }^{47}$ In the study of Manso et al, ${ }^{46}$ no AEs were registered.

\section{Dysmenorrhea}

Dysmenorrhea is defined as the presence of painful cramps of uterine origin that occur during menstruation and represents one of the most common causes of pelvic pain and menstrual disorder. The burden of dysmenorrhea is greater than any other gynecological complaint and is the leading cause of gynecological morbidity in women of reproductive age, particularly in adolescents, regardless of age, nationality, and economic status. ${ }^{50}$ In a recent network meta-analysis of 35 trials with 4383 participants, in which the efficacy of OTC analgesics for dysmenorrhea was compared, ibuprofen was recommended as the optimal option for superiority in terms of pain relief and safety profile. ${ }^{51}$ Details of two studies assessing ibuprofen arginate in primary dysmenorrhea ${ }^{52,53}$ are shown in Table 3. One study was a randomized, double-blind, cross-over trial in 83 patients assessing the efficacy of two doses (200, $400 \mathrm{mg}$ ) of ibuprofen arginate vs ibuprofen and placebo. ${ }^{52}$ In all pain-related measures ibuprofen arginate especially at doses of $400 \mathrm{mg}$ was significantly more effective than ibuprofen and both active treatments than placebo. No significant differences were found between the active treatments and placebo in the incidence of overall or individual AEs. The most common AEs were headache, nausea, and dizziness. The second study was an open trial of ibuprofen arginate $600 \mathrm{mg}$ administered during three cycles in 838 patients. $^{53}$ Marked pain relief was already reported after 15 min of drug administration. Interestingly, treatment with ibuprofen arginate had an important impact on work productivity, with significant reduction of absenteeism. AEs occurred in $3 \%$ of 


\begin{tabular}{|c|c|c|c|c|c|}
\hline & 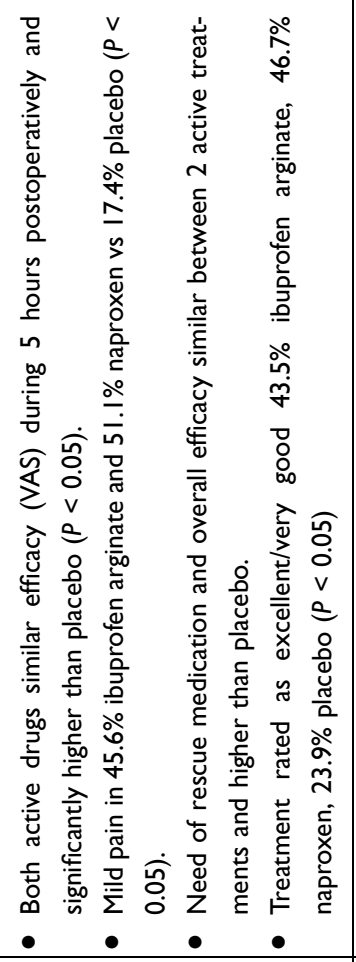 & 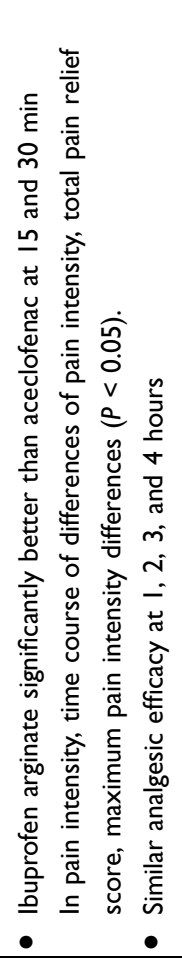 & 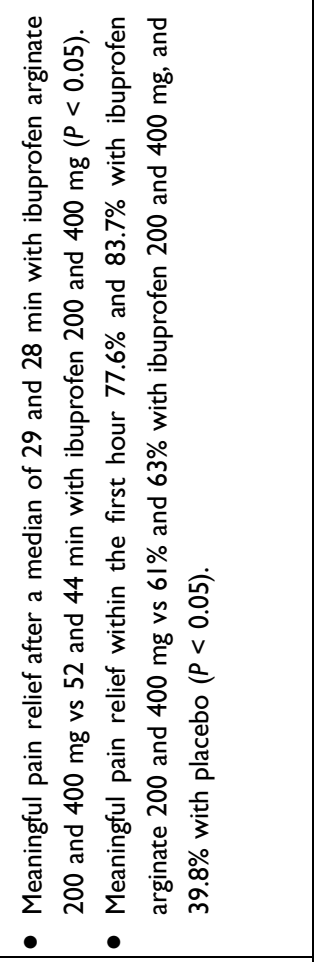 & 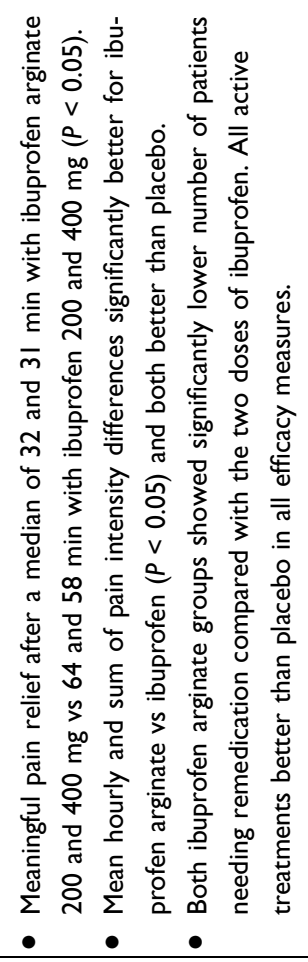 & 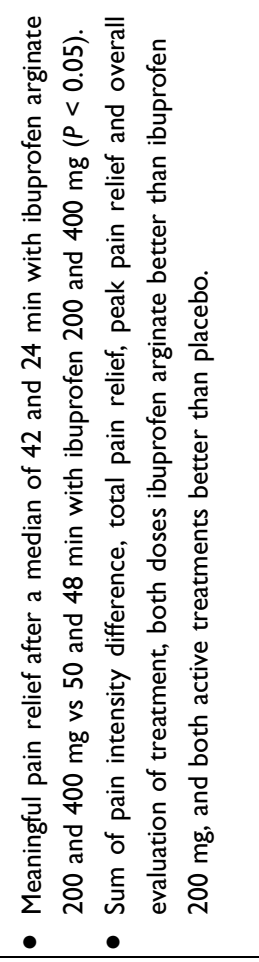 \\
\hline 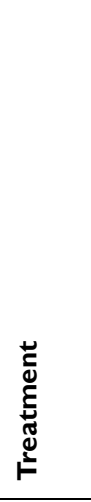 & 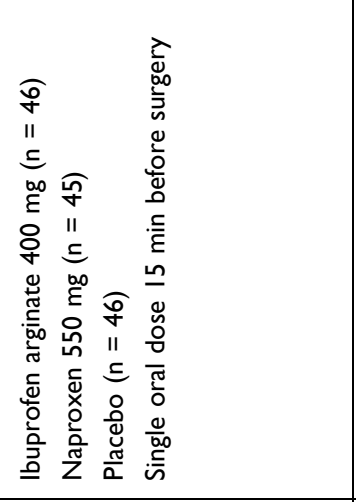 & 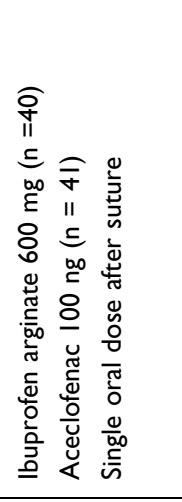 & 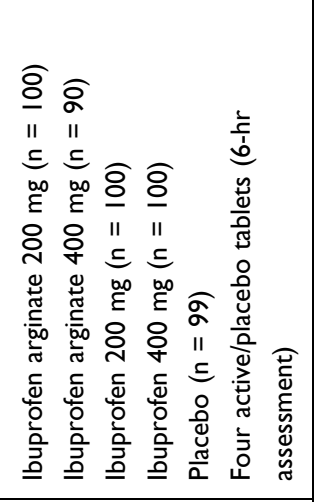 & 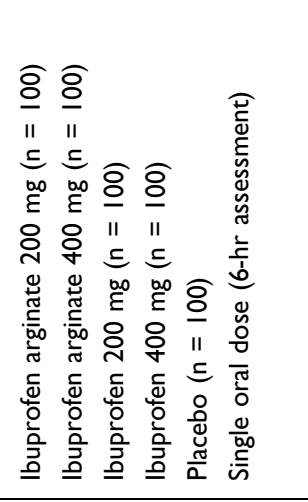 & 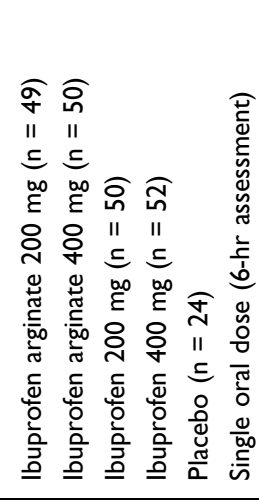 \\
\hline 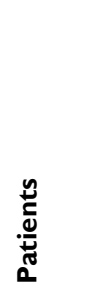 & 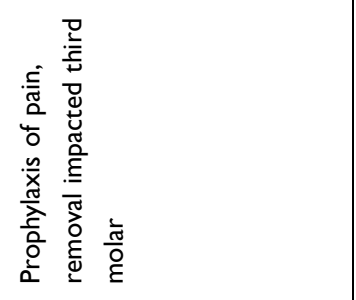 & 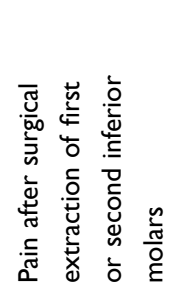 & 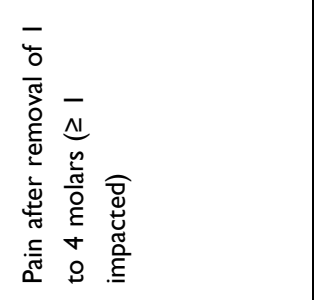 & 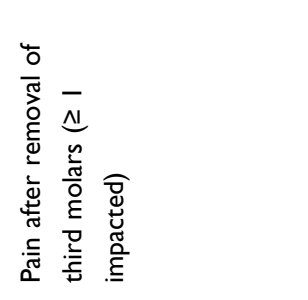 & 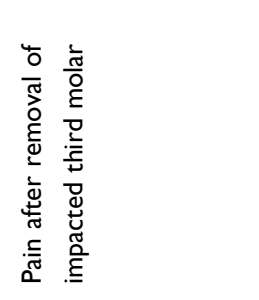 \\
\hline 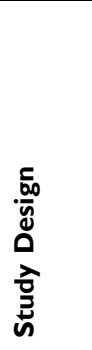 & 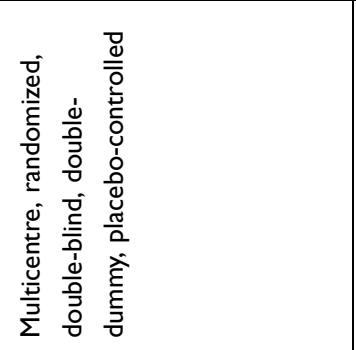 & 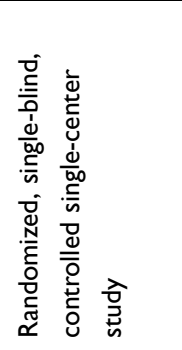 & 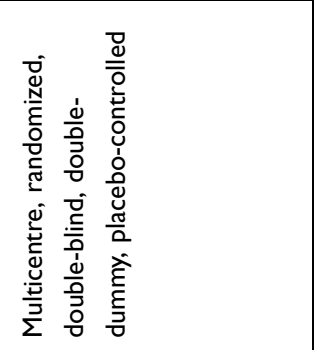 & 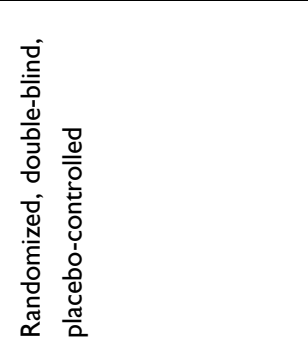 & 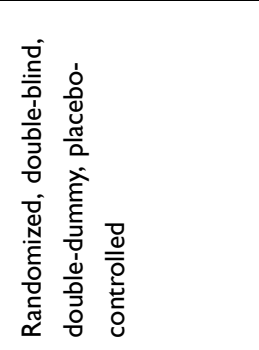 \\
\hline 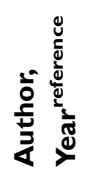 & 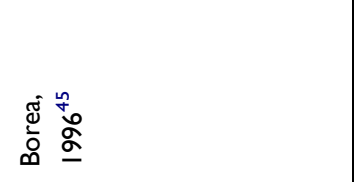 & 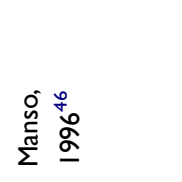 & 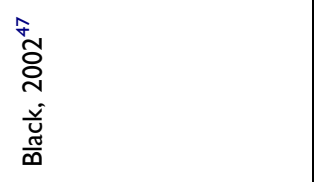 & 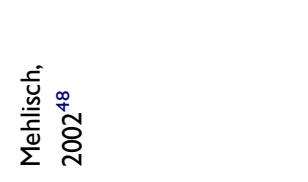 & 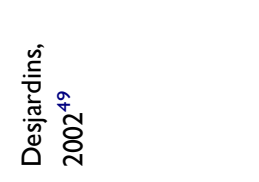 \\
\hline
\end{tabular}


Table 3 Results of Studies of the Analgesic Efficacy of Ibuprofen Arginate in Primary Dysmenorrhea and Headache

\begin{tabular}{|c|c|c|c|c|}
\hline $\begin{array}{l}\text { Author, } \\
\text { Year reference }\end{array}$ & Study Design & Patients & Treatment & Outcome \\
\hline $\begin{array}{l}\text { Mehlisch, } \\
2003^{53}\end{array}$ & $\begin{array}{l}\text { Single-center, double- } \\
\text { blind, randomized, } \\
\text { placebo-controlled, } \\
\text { double-dummy, 5-cycle, } \\
\text { crossover study }\end{array}$ & $\begin{array}{l}83 \text { patients with episodes of } \\
\text { dysmenorrhea in at least } \\
80 \% \text { of their menstrual } \\
\text { cycles during the } \\
\text { previous year }\end{array}$ & $\begin{array}{l}\text { Ibuprofen arginate } 200 \mathrm{mg} \\
\text { lbuprofen arginate } 400 \mathrm{mg} \\
\text { lbuprofen } 200 \mathrm{mg} \\
\text { lbuprofen } 400 \mathrm{mg} \\
\text { Placebo } \\
\text { Patients ingested } 4 \text { tablets (a } \\
\text { combination of active drugs } \\
\text { and/or placebo) at each cycle. }\end{array}$ & $\begin{array}{l}\text { - Time to onset of meaningful pain } \\
\text { relief was significantly faster with } \\
\text { ibuprofen arginate } 400 \mathrm{mg}(56 \mathrm{~min}) \\
\text { than with either dose of conven- } \\
\text { tional ibuprofen ( } 90 \text { and } 86 \mathrm{~min}) \\
(P<0.05) \text {. } \\
\text { - Time to onset of pain relief was } \\
\text { also significantly faster with ibu- } \\
\text { profen arginate } 400 \mathrm{mg}(P<0.05) \text {. } \\
\text { - Total pain relief values were signif- } \\
\text { cantly higher for ibuprofen arginate } \\
400 \text { mg vs } 200 \mathrm{mg} \text { and conven- } \\
\text { tional ibuprofen ( } P<0.05) \text {. } \\
\text { - A fewer patients treated with ibu- } \\
\text { profen arginate any dose remedi- } \\
\text { cated vs placebo in all cycles }(P< \\
0.05) \text {. }\end{array}$ \\
\hline $\begin{array}{l}\text { Castelo- } \\
\text { Branco, } \\
2004^{52}\end{array}$ & Open study, 3 cycles & $\begin{array}{l}838 \text { patients with a clinical } \\
\text { diagnosis of primary } \\
\text { dysmenorrhea }\end{array}$ & $\begin{array}{l}\text { Ibuprofen arginate } 600 \mathrm{mg} \text { at } \\
\text { the onset of pain followed by } \\
\text { the same dose every } 6 \mathrm{~h} \text { if } \\
\text { needed (maximum } 2400 \mathrm{mg} \text { ). }\end{array}$ & $\begin{array}{l}\text { Significant pain relief after I5 min } \\
(P<0.05) \text {. Marked decrease in pain } \\
\text { intensity at } 15 \text { and } 30 \text { min reported } \\
\text { by } 82.2 \% \text { and } 97.6 \% \text { of women. } \\
\text { - Reduction of absenteeism from } \\
\text { a mean of } 4.6 \text { to } 0.8 \mathrm{~h} \text { per cycle } \\
(P<0.00 \mathrm{I}) \text {. }\end{array}$ \\
\hline $\begin{array}{l}\text { Laveneziana, } \\
1996^{55}\end{array}$ & $\begin{array}{l}\text { Single-centre, } \\
\text { randomized double-blind } \\
\text { crossover trial }\end{array}$ & $\begin{array}{l}30 \text { patients with recurrent } \\
\text { tension-type headache }\end{array}$ & $\begin{array}{l}\text { lbuprofen arginate } 400 \mathrm{mg} \\
\text { B-cyclodextrin piroxicam } \\
20 \mathrm{mg} \\
\text { Placebo } \\
\text { Pain assessed with VAS at } 15, \\
30,60,120 \text { and } 240 \mathrm{~min}\end{array}$ & $\begin{array}{l}\text { - Ibuprofen arginate and piroxicam } \\
\text { similar efficacy, significant better } \\
\text { than placebo }(P<0.01) \\
\text { - More patients with active treat- } \\
\text { ments rated pain relief as com- } \\
\text { plete or considerable than placebo } \\
(38.5 \% \text { vs } I 5.4 \%, P=0.02) \text {. }\end{array}$ \\
\hline $\begin{array}{l}\text { Sandrini, } \\
1998^{56}\end{array}$ & $\begin{array}{l}\text { Multicenter, double- } \\
\text { blind, crossover, } \\
\text { randomized, placebo- } \\
\text { controlled trial }\end{array}$ & $\begin{array}{l}40 \text { patients with migraine } \\
\text { attacks }\end{array}$ & $\begin{array}{l}\text { Ibuprofen arginate } 400 \mathrm{mg} \text { or } \\
\text { placebo } \\
\text { Single dose during two } \\
\text { consecutive migraine attacks }\end{array}$ & $\begin{array}{l}\text { Significant pain relief at } 30 \mathrm{~min} \\
\text { after treatment }(P<0.05) \text {. } \\
\text { - Significant reduction of pain inten- } \\
\text { sity at } 1,2,4 \text { and } 6 \mathrm{~h} \text { after treat- } \\
\text { ment } \\
(P<0.00 \mathrm{I}) \text {. }\end{array}$ \\
\hline
\end{tabular}

women, with gastrointestinal complaints as the most common.

In primary dysmenorrhea, ibuprofen arginate demonstrated a fast-acting onset of pain relief and was safe and effective.

\section{Headache/Migraine}

The analgesic efficacy of ibuprofen $400 \mathrm{mg}$ for tensiontype headache was evaluated in a Cochrane systematic review, in which 12 randomized, placebo-controlled trials were included (only one study of ibuprofen arginate). ${ }^{54}$ It was found that ibuprofen $400 \mathrm{mg}$ provided an important benefit in terms of being pain free at 2 hours for patients with frequent episodic tension-type headache who have an acute headache with moderate or severe initial pain. In relation to the use of ibuprofen arginate in headache or migraine attacks, two randomized, double-blind, crossover and placebo-controlled studies have been 
published $^{55,56}$ (Table 2). In the first study, ibuprofen arginate $400 \mathrm{mg}$ was compared with $\beta$-cyclodextrin piroxicam, or placebo in 30 patients with tension-type headache. ${ }^{55}$ Pain intensity was evaluated with a visual analogue scale (VAS). Both active treatments were similar and significantly better than placebo. AEs related to treatment were not observed. In the second trial carried out in 40 patients with acute migraine attacks, each patient was treated with a single oral dose of ibuprofen arginate $400 \mathrm{mg}$ or placebo during two consecutive attacks. ${ }^{56}$ All pain measures were significantly better as compared with placebo and ibuprofen arginate was well tolerated.

\section{Other Pain Conditions}

The analgesic efficacy of ibuprofen arginate has been evaluated in different pain conditions, such as low back pain or during the postoperative period after surgical procedures. In an observational study carried out in 1817 patients with spinal pain (low back pain $63.8 \%$, cervical pain $27.2 \%$, dorsal pain $26.4 \%$ ), changes in pain intensity were evaluated with VAS at $30 \mathrm{~min}$ after a single dose of ibuprofen arginate $400 \mathrm{mg} .{ }^{57} \mathrm{~A}$ second and a third dose was allowed if pain relief was insufficient. The mean number of doses administered was 2.2 per patient. The mean VAS score decreased to 34.7 points after the first dose, to 28.0 after the second dose, and to 23.9 after the third dose. The percentage of pain decrease at $90 \mathrm{~min}$ was $62.4 \%$ as compared with baseline. The efficacy of treatment was rated as excellent or good by $64 \%$ of patients. AEs were recorded in $17 \%$ of patients with gastrointestinal symptoms as the most frequent (gastric discomfort, nausea, vomiting).

In the control of postoperative pain, different studies have evaluated the efficacy of oral ibuprofen arginate versus other NSAIDs, dipyrone, or placebo after inguinal hernia repair, ${ }^{58}$ post-cesarean section, ${ }^{59}$ suction termination of pregnancy, ${ }^{57}$ and orthopaedic surgery. ${ }^{60,61}$ In a randomized, double-blind, double-dummy, single-dose, parallel-group study, oral ibuprofen arginine $(400 \mathrm{mg})$ was compared with intramuscular (i.m.) morphine sulphate (5 or $10 \mathrm{mg}$ ) for postoperative pain relief after orthopaedic surgery in 120 patients. ${ }^{61}$ Assessments of pain intensity and pain relief up to the completion of the study at 240 min showed no significant differences between the two active drugs, with similar AEs. In another randomized, double-blind, double-dummy study of 106 patients undergoing total hip replacement surgery, oral ibuprofen arginate $400 \mathrm{mg}$ was compared with i.m. dipyrone $2 \mathrm{~g}$ and placebo. ${ }^{62}$ Pain-related variables were evaluated up to 300 min after treatment, and no significant differences between ibuprofen arginate and dipyrone were found, but both active treatments were significantly better than placebo. Therefore, oral ibuprofen arginate $400 \mathrm{mg}$ has proven to be a useful alternative to parenteral analgesic agents in the management of postoperative pain following orthopaedic procedures.

This narrative review provides useful clinically oriented information but has the limitation that it is not a systematic review and was not designed to answer a specific question. However, it presents an overview of the research landscape of ibuprofen arginate, which is a popular OTC analgesic in some countries.

\section{Summary}

Arginine salt of ibuprofen is an alternative formulation specifically designed to improve the absorption of ibuprofen as compared with the conventional ibuprofen. The shortening in the absorption time, however, did not imply a faster drug elimination. This review provides useful insights into the experience with the use of ibuprofen arginate for the management of acute pain in randomized double-blind controlled studies and real-life settings. Ibuprofen arginate is clinically useful today for the management of acute mild and moderate pain secondary to different conditions in which rapid onset of analgesia is required. Clinical studies evaluating ibuprofen arginate have so far demonstrated an effective, safe and welltolerated profile. Ibuprofen arginate can be used in clinical practice based on individualized patient needs.

\section{Acknowledgments}

The author thanks Zambon for facilitating the clinical trials that have been the subject of this review.

\section{Author Contributions}

The author made substantial contributions to conception and design, acquisition of data, or analysis and interpretation of data; took part in drafting the article or revising it critically for important intellectual content; agreed to submit to the current journal; gave final approval of the version to be published; and agree to be accountable for all aspects of the work.

\section{Disclosure}

The author has no conflict of interest to be disclosed. 


\section{References}

1. Sinatra R. Causes and consequences of inadequate management of acute pain. Pain Med. 2010;11(12):1859-1871. doi:10.1111/j.15264637.2010.00983.x

2. Henschke N, Kamper SJ, Maher CG. The epidemiology and economic consequences of pain. Mayo Clin Proc. 2015;90(1):139-147. doi:10.1016/j.mayocp.2014.09.010

3. Kent ML, Tighe PJ, Belfer I, et al. The ACTTION-APS-AAPM Pain Taxonomy (AAAPT) Multidimensional Approach to Classifying Acute Pain Conditions. Pain Med. 2017;18(5):947-958. doi:10.1093/ $\mathrm{pm} / \mathrm{pnx} 019$

4. Goldberg DS, McGee SJ. Pain as a global public health priority. BMC Public Health. 2011;11:770. doi:10.1186/1471-2458-11-770

5. McCarberg BH, Nicholson BD, Todd KH, Palmer T, Penles L. The impact of pain on quality of life and the unmet needs of pain management: results from pain sufferers and physicians participating in an Internet survey. Am $J$ Ther. 2008;15(4):312-320. doi:10.1097/ MJT.0b013e31818164f2

6. GBD 2017 Disease and Injury Incidence and Prevalence Collaborators. Global, regional, and national incidence, prevalence, and years lived with disability for 354 diseases and injuries for 195 countries and territories, 1990-2017: a systematic analysis for the Global Burden of Disease Study 2017. Lancet. 2018;392 (10159):1789-1858. doi:10.1016/S0140-6736(18)32279-7

7. Rice AS, Smith BH, Blyth FM. Pain and the global burden of disease. Pain. 2016;157(4):791-796. doi:10.1097/j.pain.0000000000000454

8. Mills SEE, Nicolson KP, Smith BH. Chronic pain: a review of its epidemiology and associated factors in population-based studies. $\mathrm{Br}$ J Anaesth. 2019;123(2):e273-e283. doi:10.1016/j.bja.2019.03.023

9. Robaux S, Bouaziz H, Cornet C, Boivin JM, Lefèvre N, Laxenaire MC. Acute postoperative pain management at home after ambulatory surgery: a French pilot survey of general practitioners' views. Anesth Analg. 2002;95(5):1258-1262. doi:10.1097/00000539200211000-00029

10. Eggen AE. The Tromsø Study: frequency and predicting factors of analgesic drug use in a free-living population (12-56 years). $J$ Clin Epidemiol. 1993;46(11):1297-1304. doi:10.1016/0895-4356(93)90098-L

11. Dale O, Borchgrevink PC, Fredheim OMS, et al. Prevalence of use of non-prescription analgesics in the Norwegian HUNT3 population: impact of gender, age, exercise and prescription of opioids. BMC Public Health. 2015;15:461. doi:10.1186/s12889015-1774-6

12. Turunen JH, Mäntyselkä PT, Kumpusalo EA, Ahonen RS. Frequent analgesic use at population level: prevalence and patterns of use. Pain. 2005;115(3):374-381. doi:10.1016/j.pain.2005.03.013

13. Paulose-Ram R, Hirsch R, Dillon C, Losonczy K, Cooper M, Ostchega Y. Prescription and non-prescription analgesic use among the US adult population: results from the third National Health and Nutrition Examination Survey (NHANES III). Pharmacoepidem Drug Safe. 2003;12:315-326. doi:10.1002/pds.755

14. Moore N. Ibuprofen: a journey from prescription to over-the-counter use. J R Soc Med. 2007;100(Suppl 48):2-6.

15. Moore RA, Wiffen PJ, Derry S, Maguire T, Roy YM, Tyrrell L. Nonprescription (OTC) oral analgesics for acute pain - an overview of Cochrane reviews. Cochrane Database Syst Rev. 2015;(11): CD010794. doi:10.1002/14651858.CD010794.pub2

16. Davies NM. Clinical pharmacokinetics of ibuprofen. The first 30 years. Clin Pharmacokinet. 1998;34(2):101-154. doi:10.2165/ 00003088-199834020-00002

17. Ikuta H, Kawase A, Iwaki M. Stereoselective pharmacokinetics and chiral inversion of ibuprofen in adjuvant-induced arthritic rats. Drug Metab Dispos. 2017;45(3):316-324. doi:10.1124/dmd.116.073239

18. Hao H, Wang G, Sun J. Enantioselective pharmacokinetics of ibuprofen and involved mechanisms. Drug Metab Rev. 2005;37(1):215234. doi:10.1081/dmr-200047999
19. Evans AM. Comparative pharmacology of $\mathrm{S}(+)$-ibuprofen and (RS)-ibuprofen. Clin Rheumatol. 2001;20(Suppl 1):S9-S14. doi:10.1007/BF03342662

20. Cattaneo D, Clementi E. Clinical pharmacokinetics of ibuprofen arginine. Curr Clin Pharmacol. 2010;5(4):239-245. doi:10.2174/ 157488410793352012

21. Fornasini G, Monti N, Brogin G, et al. Preliminary pharmacokinetic study of ibuprofen enantiomers after administration of a new oral formulation (ibuprofen arginine) to healthy male volunteers. Chirality. 1997;9(3):297-302. doi:10.1002/(SICI)1520-636X(1997) 9:3<297::AID-CHIR16>3.0.CO;2-I

22. Mazaleuskaya LL, Theken KN, Gong L, et al. PharmGKB summary: ibuprofen pathways. Pharmacogenet Genomics. 2015;25(2):96-106. doi:10.1097/FPC.0000000000000113

23. Ceppi Monti N, Gazzaniga A, Gianesello V, Stroppolo F, Lodola E. Activity and pharmacokinetics of a new oral dosage form of soluble ibuprofen. Arzneimittelforschung. 1992;42(4):556-559.

24. Sádaba B, Campanero MA, Muñoz-Juarez MJ, et al. A comparative study of the pharmacokinetics of ibuprofen arginate versus dexibuprofen in healthy volunteers. Eur J Clin Pharmacol. 2006;62 (10):849-854. doi:10.1007/s00228-006-0180-5

25. Sostres C, Gargallo CJ, Lanas A. Nonsteroidal anti-inflammatory drugs and upper and lower gastrointestinal mucosal damage. Arthritis Res Ther. 2013;15 Suppl 3(Suppl3):S3. doi:10.1186/ar4175

26. Henry D, McGettigan P. Epidemiology overview of gastrointestinal and renal toxicity of NSAIDs. Int $J$ Clin Pract Suppl. 2003;135:43-49.

27. Hernández-Díaz S, Rodríguez LA. Association between nonsteroidal anti-inflammatory drugs and upper gastrointestinal tract bleeding/ perforation: an overview of epidemiologic studies published in the 1990s. Arch Intern Med. 2000;160(14):2093-2099. doi:10.1001/ archinte.160.14.2093

28. Castellsague J, Riera-Guardia N, Calingaert B, et al. Individual NSAIDs and upper gastrointestinal complications: a systematic review and meta-analysis of observational studies (the SOS project). Drug Saf. 2012;35(12):1127-1146. doi:10.2165/11633470000000000-00000

29. Furey SA, Waksman JA, Dash BH. Nonprescription ibuprofen: side effect profile. Pharmacotherapy. 1992;12(5):403-407.

30. DeArmond B, Francisco CA, Lin JS, et al. Safety profile of over-thecounter naproxen sodium. Clin Ther. 1995;17(4):587-601. doi:10.1016/0149-2918(95)80036-0

31. Rainsford KD, Roberts SC, Brown S. Ibuprofen and paracetamol: relative safety in non-prescription dosages. $J$ Pharm Pharmacol. 1997;49(4):345-376.

32. Kellstein DE, Waksman JA, Furey SA, Binstok G, Cooper S. The safety profile of nonprescription ibuprofen in multiple-dose use: a meta-analysis. J Clin Pharmacol. 1999;39(5):520-532.

33. Dijkstra G, van Goor H, Jansen PL, Moshage H. Targeting nitric oxide in the gastrointestinal tract. Curr Opin Investig Drugs. 2000;5 (5):529-536.

34. Konturek JW, Fischer H, Gromotka PM, Konturek SJ, Domschke W. Endogenous nitric oxide in the regulation of gastric secretory and motor activity in humans. Aliment Pharmacol Ther. 1999;13 (12):1683-1691. doi:10.1046/j.1365-2036.1999.00598.x

35. Mollace V, Muscoli C, Masini E, Cuzzocrea S, Salvemini D. Modulation of prostaglandin biosynthesis by nitric oxide and nitric oxide donors. Pharmacol Rev. 2005;57(2):217-252. doi:10.1124/pr.57.2.1

36. De Palma C, Di Paola R, Perrotta C, et al. Ibuprofen-arginine generates nitric oxide and has enhanced anti-inflammatory effects. Pharmacol Res. 2009;60(4):221-228. doi:10.1016/j.phrs. 2009.06.002

37. Jiménez D, Martin MJ, Pozo D, et al. Mechanisms involved in protection afforded by L-arginine in ibuprofen-induced gastric damage: role of nitric oxide and prostaglandins. Dig Dis Sci. 2002;47(1):44-53. doi:10.1023/A:1013203217788 
38. Martín Calero MJ, Jiménez MD, Alarcón de la Lastra C, et al. Protective effect of L-arginine against ibuprofen-induced gastric injury in rats. Pharm Sci. 1997;3:609-612.

39. Gisbert JP, Abad-Santos F, Novalbos J, et al. Comparison of gastric endoscopic lesions and tolerability to ibuprofen and ibuprofen-arginate in healthy subjects. $J$ Clin Gastroenterol. 2005;39(9):834-835. doi:10.1097/01.mcg.0000177259.95562.0a

40. Gallego-Sandín S, Novalbos J, Rosado A, et al. Effect of ibuprofen on cyclooxygenase and nitric oxide synthase of gastric mucosa: correlation with endoscopic lesions and adverse reactions. Dig Dis Sci. 2004;49(9):1538-1544. doi:10.1023/B:DDAS.0000042261.22387.06

41. Kirkby NS, Tesfai A, Ahmetaj-Shala B, et al. Ibuprofen arginate retains eNOS substrate activity and reverses endothelial dysfunction: implications for the COX-2/ADMA axis. FASEB J. 2016;30 (12):4172-4179. doi:10.1096/fj.201600647R

42. Kittel A, Maas R. Pharmacology and clinical pharmacology of methylarginines used as inhibitors of nitric oxide synthases. Curr Pharm Des. 2014;20(22):3530-3547. doi:10.2174/13816128113196660750

43. Bouras G, Deftereos S, Tousoulis D, et al. Asymmetric Dimethylarginine (ADMA): a promising biomarker for cardiovascular disease? Curr Top Med Chem. 2013;13(2):180-200. doi:10.2174/ 1568026611313020007

44. Urquhart E. Analgesic agents and strategies in the dental pain model. J Dent. 1994;22(6):336-341. doi:10.1016/0300-5712(94)90084-1

45. Borea G, Monopoli R, Colantoni A. Ibuprofen arginine vs naproxen sodium as prophylactic oral treatment of pain due to dental surgery. Clin Drug Invest. 1996;11(Suppl1):33-40. doi:10.2165/00044011199600111-00008

46. Manso FJ, Bascones A, Maqueda MJ, Vadillo JM. Estudio controlado sobre la eficacia y tolerabilidad de ibuprofeno-arginina vs. aceclofenaco en el control del dolor post-extracción quirúrgica de molares inferiores [Controlled study on the efficacy and tolerability of ibuprofen-arginine vs.Aceclofenac in the control of pain after surgical extraction of lower molars]. Av Odontoestomatol. 1996;12:531-536.

47. Black P, Max MB, Desjardins P, Norwood T, Ardia A, Pallotta T. A randomized, double-blind, placebo-controlled comparison of the analgesic efficacy, onset of action, and tolerability of ibuprofen arginate and ibuprofen in postoperative dental pain. Clin Ther. 2002;24(7):1072-1089. doi:10.1016/S0149-2918(02)80020-0

48. Mehlisch DR, Ardia A, Pallotta T. A controlled comparative study of ibuprofen arginate versus conventional ibuprofen in the treatment of postoperative dental pain. J Clin Pharmacol. 2002;42(8):904-911. doi:10.1177/009127002401102821

49. Desjardins P, Black P, Papageorge M, et al. Ibuprofen arginate provides effective relief from postoperative dental pain with a more rapid onset of action than ibuprofen. Eur J Clin Pharmacol. 2002;58(6):387-394. doi:10.1007/s00228-002-0491-0

50. De Sanctis V, Soliman A, Bernasconi S, et al. Primary dysmenorrhea in adolescents: prevalence, impact and recent knowledge. Pediatr Endocrinol Rev. 2015;13(2):512-520.
51. Nie W, Xu P, Hao C, Chen Y, Yin Y, Wang L. Efficacy and safety of over-the-counter analgesics for primary dysmenorrhea: a network meta-analysis. Medicine. 2020;99(19):e19881. doi:10.1097/ MD.0000000000019881

52. Castelo-Branco C, Casals G, Haya J, Cancelo MJ, Manasanch J. Efficacy and safety of Ibuprofen arginine in the treatment of primary dysmenorrhoea. Clin Drug Investig. 2004;24(7):385-393. doi:10.2165/00044011-200424070-00002

53. Mehlisch DR, Ardia A, Pallotta T. Analgesia with ibuprofen arginate versus conventional ibuprofen for patients with dysmenorrhea: a crossover trial. Curr Ther Res Clin Exp. 2003;64(6):327-337. doi:10.1016/S0011-393X(03)00104-8

54. Derry S, Wiffen PJ, Moore RA, Bendtsen L. Ibuprofen for acute treatment of episodic tension-type headache in adults. Cochrane Database Syst Rev. 2015;2015(7):CD011474. doi:10.1002/ 14651858.CD011474.pub2

55. Laveneziana D, Speranza R, Raulli P, Paredi G. Comparative efficacy of ibuprofen arginine and betacyclodextrin piroxicam as treatment for tension-type headache. Clin Drug Invest. 1996;11(Suppl 1):22-26. doi:10.2165/00044011-199600111-00006

56. Sandrini G, Franchini S, Lanfranchi S, Granella F, Manzoni GC, Nappi G. Effectiveness of ibuprofen-arginine in the treatment of acute migraine attacks. Int $J$ Clin Pharmacol Res. 1998;18 (3):145-150.

57. Rodríguez MJ. Eficacia analgésica y tolerabilidad de ibuprofenarginina en el dolor del raquis. Resultados de un estudio multicéntrico. Rev Soc Esp Dolor. 1996:1-4.

58. Laveneziana D, Riva A, Bonazzi M, Cipolla M, Miglavacca S. Comparative efficacy of oral ibuprofen arginine and intramuscular ketorolac in patients with postoperative pain. Clin Drug Invest. 1996;11(Suppl 1):8-14. doi:10.2165/00044011-199600111-00004

59. Pagnoni B, Vignali M, Colella S, Monopoly R, Tiengo M. Comparative efficacy of oral ibuprofen arginine and intramuscular ketorolac in patients with post-cesarean section pain. Clin Drug Invest. 1996;11(Suppl 1):15-21. doi:10.2165/00044011-19960011100005

60. Pagnoni B, Ravelli A, Degradi L, Rossi R, Tiengo M. Clinical efficacy of ibuprofen arginine in the management of postoperative pain associated with suction termination of pregnancy. Clin Drug Invest. 1996;11(Suppl 1):27-32. doi:10.2165/00044011-19960011100007

61. Mansfield M, Firth F, Glynn C, Kinsella J. A comparison of ibuprofen arginine with morphine sulphate for pain relief after orthopaedic surgery. Eur J Anaesthesiol. 1996;13(5):492-497. doi:10.1097/ 00003643-199609000-00013

62. De Miguel Rivero C, García Araujo C, Mella Sousa M, et al. Comparative efficacy of oral ibuprofen-arginine, intramuscular magnesic dipyrone and placebo in patients with postoperative pain following total hip replacement. Clin Drug Invest. 1997;14:276-285. doi:10.2165/00044011-199714040-00005
Journal of Pain Research

\section{Publish your work in this journal}

The Journal of Pain Research is an international, peer reviewed, open access, online journal that welcomes laboratory and clinical findings in the fields of pain research and the prevention and management of pain. Original research, reviews, symposium reports, hypothesis formation and commentaries are all considered for publication. The manuscript management system is completely online and includes a very quick and fair peer-review system, which is all easy to use. Visit http:// www.dovepress.com/testimonials.php to read real quotes from published authors. 